\title{
Breed, sex and anatomical location-specific gene expression profiling of the porcine skeletal muscles
}

Jie Zhang ${ }^{1}$, Chaowei Zhou' ${ }^{1}$ Jideng Ma', Lei Chen², Anan Jiang ${ }^{1}$, Li Zhu' ${ }^{1}$, Surong Shuai', Jinyong Wang ${ }^{2}$, Mingzhou Li $i^{* *}$ and Xuewei $\mathrm{Li}^{\mathrm{i}^{*}}$

\begin{abstract}
Background: Skeletal muscle is one of the most important economic traits in agricultural animals, especially in pigs. In the modern pig industry, lean type pigs have undergone strong artificial selection for muscle growth, which has led to remarkable phenotypic variations compared with fatty type pigs, making these different breeds an ideal model for comparative studies.

Results: Here, we present comprehensive gene expression profiling for the white (longissimus dorsi muscle) and the red (psoas major muscle) skeletal muscles among male and female fatty Rongchang, feral Tibetan and lean Landrace pigs, using a microarray approach. We identified differentially expressed genes that may be associated the phenotypic differences of porcine muscles among the breeds, between the sexes and the anatomical locations. We also used a clustering method to identify sets of functionally coexpressed genes that are linked to different muscle phenotypes. We showed that, compared with the white muscles, which primarily modulate metabolic processes, the red muscles show a tendency to be a risk factor for inflammation and immune-related disorders.

Conclusions: This analysis presents breed-, sex- and anatomical location-specific gene expression profiles and further identified genes that may be associated with the phenotypic differences in porcine muscles among breeds, between the sexes and the anatomical locations.
\end{abstract}

Keywords: Gene expression, Microarray, Muscle, Pig

\section{Background}

Skeletal muscle is the most abundant tissue, comprising approximately $50 \%$ of the total body mass in mammals [1]. It is not only a motor organ, but also part of the endocrine system, participating in the regulation of whole body metabolism [2]. Skeletal muscle, as a highly heterogeneous tissue, is composed of a variety of functionally diverse myofibre types [3]; mainly the red (type I and IIa) and the white (type IIb) fibers. Red skeletal muscles, such as the psoas major muscles (PMM), have a higher percentage of capillaries, myoglobin, lipids and mitochondria [4], making them a better aerobic machine

\footnotetext{
*Correspondence: mingzhou.li@163.com; xuewei.li@sicau.edu.cn ${ }^{1}$ Institute of Animal Genetics \& Breeding, College of Animal Science \& Technology, Sichuan Agricultural University, Ya'an, Sichuan 625000, China Full list of author information is available at the end of the article of the article
}

than the paler-appearing white muscle [5]. White skeletal muscles, such as the longissimus doris muscles (LDM) [4], are required for anaerobic glycolytic metabolism to support the high transient energy demand [6].

Deciphering the different gene expression patterns between the different tissues would aid in our understanding of their distinct metabolic features. Mo et al. identified various candidate genes involved in cell adhesion, energy balance, muscle atrophy and myogenesis by comparing patterns of gene expression in three independent mouse models of Kennedy disease/spinal bulbar muscular atrophy [7]. Wolfs et al. reported that coexpressed immune and metabolic genes are associated with plasma high density lipoprotein and glucose levels by comparing genome-wide transcription profiling of subcutaneous and visceral adipose tissues
C Biomed Central

(c) 2013 Zhang et al.; licensee BioMed Central Ltd. This is an Open Access article distributed under the terms of the Creative Commons Attribution License (http://creativecommons.org/licenses/by/2.0), which permits unrestricted use, distribution, and reproduction in any medium, provided the original work is properly cited. 
obtained from obese patients [8]. Previous reports also suggested that ethnic group and sex are also the important factors that affect physiological and biochemical features of skeletal muscles in mammals [9-12].

Pigs are important agricultural animals and ideal biomedical models [13]. In the modern pig industry, pigs have undergone strong artificial selection for lean meat or adipose production, which has led to remarkable phenotypic variations, making these different breeds a perfect model for comparative studies $[14,15]$. Using a microarray approach, Bai et al. noted that most differentially expressed genes between porcine PMM and LDM were of mitochondrial origin [16]. Li et al. (2010) reported that the differentially expressed genes between the LDM and soleus muscle of Chinese Meishan pigs were mainly over-represented in various signaling pathways (particularly TGF- $\beta$, MAPK, Wnt, mTOR and insulin pathways) [17]. Nonetheless, the different gene expression profiles associated with breed and sex in skeletal muscle tissues has been long overdue, and elucidation of this information will benefit the development of strategies for skeletal muscle manipulation.

Here, using a microarray technology, we present a comprehensive survey of gene expression profiles between two phenotypically distinct skeletal muscles and sexes of three well-defined pig breeds displaying distinct muscle phenotypes. This study will contribute to our understanding of the molecular process of muscle fiber type formulation and provide a theoretical basis for breed and meat quality improvement in pigs.

\section{Results and discussion}

\section{Phenotypic measurements}

Our previous report, based on the same individuals, demonstrated that the myofibre cross-sectional area (CSA) and myofibre ratio were significant different between the two skeletal tissues, between the male and female and among the three breeds [18] (Additional file 1: Figure S1). In addition, 24 representative metabolism indicators in serum also revealed the same ranking from the leaner Landrace, the wild Tibetan and the fatty Rongchang pigs [18] (Additional file 2: Table S1).

\section{Functional enrichment analysis of differentially expressed genes}

Out of 4,309 high-confidence and well annotated probetargeted genes (Additional file 3: Tables S2), we identified five (0.12\%), $444(10.3 \%)$ and 1,359 (31.54\%) differentially expressed genes (DEGs) between the sexes and the two tissues, and among the three breeds $(P<0.05$, three-way ANOVA, $n=3$ per breed per sex per tissue) (Additional file 4: Tables S3), respectively. These DEGs could discriminate the different breeds, sexes and tissues
(Figure 1). The high number of DEGs among three pig breeds implies distinct muscle features among different pig breeds. In addition, the biological replicates correlated with each other (average Spearman's $r=0.99$, Figure 1), which suggested experimental reliability and further highlighted the low variation in gene expression profiles across different individuals.

We found that the breed-specific DEGs were significantly enriched in the Gene Ontology (GO) categories of protein metabolism (i.e. protein metabolic process, translation, protein folding and protein complex assembly) and RNA metabolism (i.e. mRNA processing and RNA metabolic process) (Figure 2A). Various wellknown genes involved in growth and development of skeletal muscles were identified. For example, myostatin $(M S T N)$, a secreted transforming growth factor (TGF) beta protein family member, inhibits the differentiation and growth of muscle and Akt-induced protein synthesis [19]. The expression level of MSTN was highest in Rongchang pigs and lowest in Landrace pigs, which is consistent with the breeds' characteristics (Figure 2A). Myogenin (MYOG) transforms potential mesoderm cells to sarcoblasts, and has a critical role in the terminal differentiation of the specified muscle cells [20,21]. Among the three breeds, the expression levels of MYOG were highest in Tibetan pigs and lowest in Rongchang pigs (Figure 2A). This result suggests that the breed-specific differences in muscle were mainly related to the protein translation process, which is consistent with previous studies [22-24]. Additionally, we found breed-specific DEGs that were over-represented in the neurological system process (370 DEGs, $P=0.01$ ), which highlights the important roles of myoblast lineage and innervations in the diversification of skeletal muscle fiber types.

Tissue-specific DEGs were significantly enriched in energy metabolism related processes (i.e. generation of precursor metabolites and energy, respiratory electron transport chain, fatty acid metabolic process, oxidative phosphorylation, lipid metabolic process, tricarboxylic acid cycle and coenzyme metabolic process) (Figure 2B), which is consistent with the distinct features of energy expenditure regulation between the LDM and PMM [25]. Energy availability is important in the formation of mature muscle fibers and is essential for muscle proliferation and differentiation. Louis et al. reported that the energy content of cultured satellite cells is related to the hypertrophy of myofibres in vitro, which indicated a direct connection between energy metabolism and myogenesis [26]. Cagnazzo et al. also demonstrated that myogenic differentiation and energy metabolism were directly connected processes [27]. Genes involved in energy metabolism were identified. For example, $M D H 1$, $P D K 3$ and GOT1 play important roles in sympatheticinduced metabolism, which is involved in modulating the 

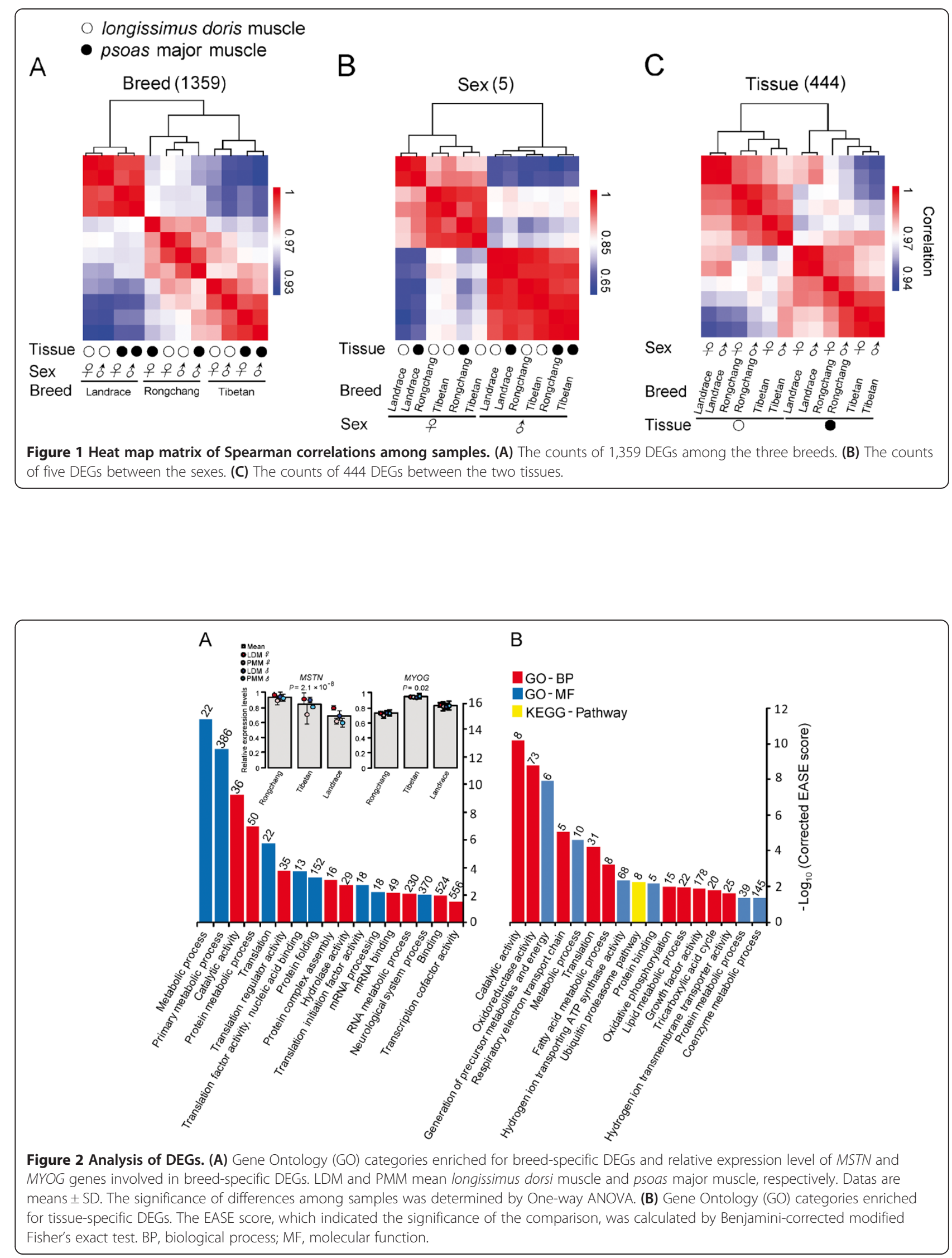
activity of glyceroneogenesis [28]. MDH1, PDK3 and GOT1 showed lower gene expression levels in the LDM than in PMM (Additional file 5: Figure S2), which agreed with previous reports [29-32]. We also found that tissuespecific DEGs were over-represented in the ubiquitinproteasome pathway (Figure 2B), which plays a critical role in the adaptation of skeletal muscle to persistent decreases or increases in muscle activity. The ubiquitinproteasome pathway is constitutively active in muscle and continually regulates protein turnover [33].

We only identified five DEGs between the sexes, of which two are X-linked genes (ubiquitin specific peptidase 9 (USP9X) and synapse associated protein 1 (SYAP1)) that exhibited higher expression levels in females than in males $\left(P<10^{-5}\right.$, Student's $t$-test; Figure $3 \mathrm{~A}$ and Figure $\left.3 \mathrm{~B}\right)$. USP9X, as a novel mTORC1 and -2 binding partner, negatively regulates mTOR activity and further affects the differentiation of skeletal muscle [34]. SYAP1 plays an important role in cancer formation [35]. By contrast, a Y-linked gene, eukaryotic translation initiation factor 1A (EIF1AY) exhibited significantly higher expression in males than in females $\left(P=5.38 \times 10^{-6}\right.$, Student's $t$-test; Figure $3 C$ ), which could affect the maximal rate of protein biosynthesis [36]. Additionally, two DEGs are located in the autosome: acyl-CoA thioesterase 9 (ACOT9) and the deltex 3-like (DTX3L), which exhibited higher mRNA expression levels in males than in females $\left(P<10^{-4}\right.$, Student's $t$-test; Figure 3D and Figure 3E). ACOT9, as an important enzyme involved in fatty acid metabolism, is located in the mitochondrion and provides energy through the citric acid cycle [37]. The higher mRNA expression level of ACOT9 in males reflects the fact that male muscles have a higher capacity for anaerobic metabolism and generate a higher maximum power output than female muscles [11]. DTX3L plays an important role in the Notch signaling pathway and controls myogenesis; its higher expression in male muscles is consistent with male pigs having more and larger muscles than the females [38].

\section{Validation of gene expression changes by Quantitative PCR (Q-PCR)}

Six genes (ADIPOR1, ADIPOR2, CAV1, CAV2, INSIG1, and $M D H 1$ ) were selected to confirm their expression patterns using Q-PCR. The results indicated that the expression patterns of these genes were consistent with the microarray (average Pearson's $r=0.86$; Additional file 6: Figure S3).

\section{Analysis of coexpressed gene modules}

To extract more biological information within the genome-wide expression data set that could not be provided by individual, we constructed coexpressed gene modules and performed association analysis with the phenotypic traits, as did previous reports [8].

We identified eight and six gene modules for LDM and PMM (more than 100 genes per module), representing
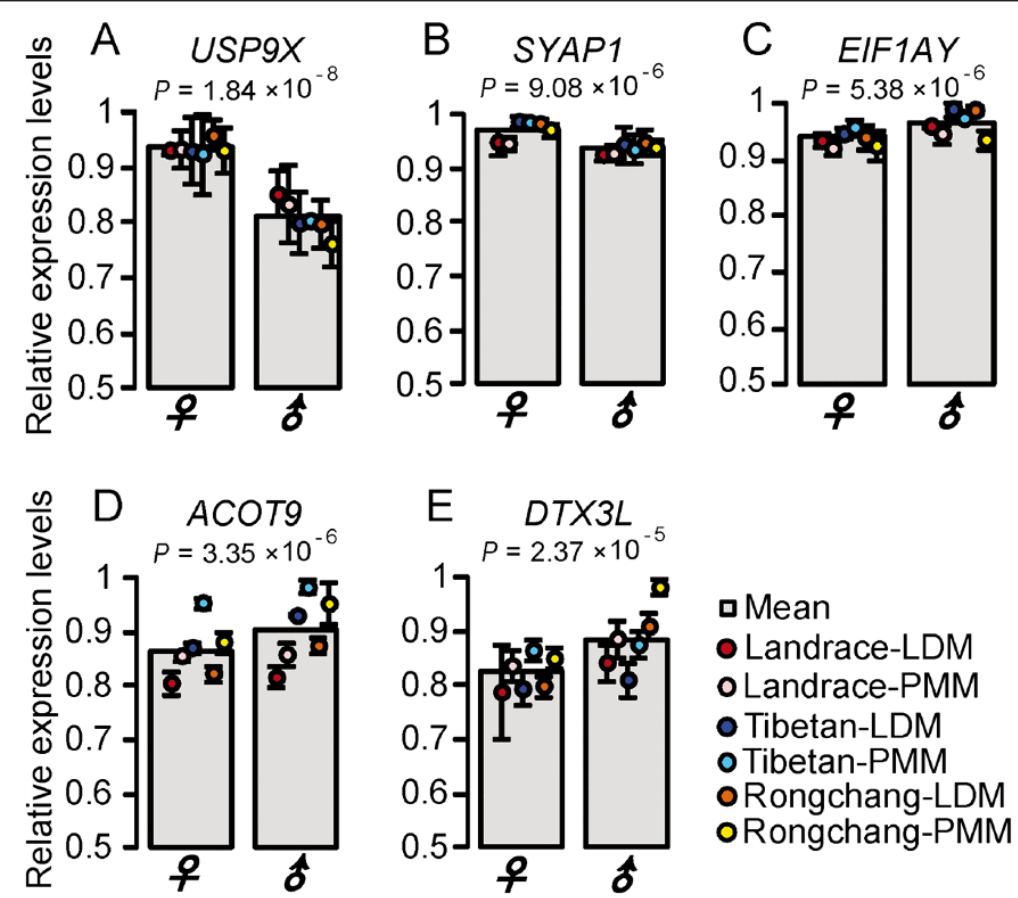

Figure 3 Relative expression levels of sex-specific DEGs. (A) USP9X gene; (B) SYAP1 gene; (C) EIF1AY gene; (D) ACOT9 gene; (E) DTX3L gene. LDM and PMM mean longissimus dorsi muscle and psoas major muscle, respectively. Data are means \pm SD. The significance of differences among samples was determined by Student's t-test. 

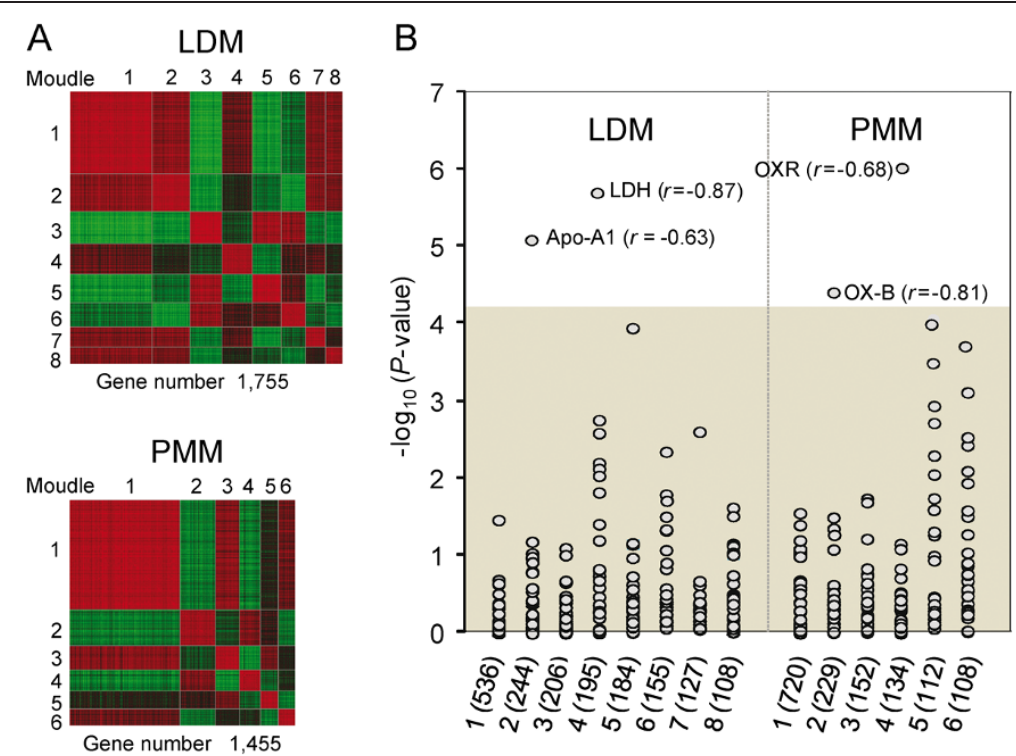

Figure 4 Analysis of coexpressed gene modules in LDM and PMM. (A) Heat map of coexpressed gene modules in longissimus dorsi muscle (LDM) and psoas major muscle (PMM). Gene pairs strongly positively or negatively correlated are shown in red or green, respectively. (B) Correlations between coexpressed gene modules in two muscle tissues and phenotypic traits. -Log $P$-values for Spearman correlation coefficients between the values of the modules and the different phenotypic traits are shown. The gray shadow represents a highly stringent Bonferroni corrected $P$-value of 0.05 .

1,755 and 1,455 genes, respectively (Additional file 7: Table S4A and 4B). Expressions of genes within a single gene module are strongly correlated, whereas genes that belong to different modules generally show no significant coexpression (Figure 4A). As shown in Additional file 8: Table S5, eight gene modules of LDM and PMM significantly overlapped with each other $(P<0.01$, Fisher's exact tests), which implies that similar gene expression patterns are involved in basic physiological and biochemical processes of skeletal muscle.

We identified two coexpressed gene modules in LDM that were significantly negatively correlated with the amount of apolipoprotein A1 (Apo-A1) (Spearman's $r=$ $-0.63, P=8.71 \times 10^{-6}$ ) and lactate dehydrogenase (LDH) (Spearman's $r=-0.87, P=2.05 \times 10^{-6}$, Figure $4 \mathrm{~B}$ ) in serum, which are primarily involved in metabolic processes. Apo-A1 is a major protein component of high density lipoprotein in serum and has been suggested to be tightly linked to muscle differentiation [39]. LDH is a marker of the oxidative and glycolytic capacities of the muscle, and converts pyruvate to lactate when oxygen is absent or in short supply [40]. The genes within these two gene modules were mainly enriched in the categories of protein metabolic process (94 genes, $P=5.03 \times 10^{-4}$ ), cellular metabolic process (100 genes, $\left.P=5.22 \times 10^{-6}\right)$, cellular nitrogen compound metabolic process (60 genes, $P=0.048)$ and primary metabolic process $\left(127\right.$ genes, $\left.P=4.55 \times 10^{-8}\right)$ (Table 1). These findings confirmed the report that the LDM is mainly associated with metabolic rate [41].
We also found that two coexpressed gene modules in PMM were significantly negatively correlated with amount of orexin-B (OX-B) (Spearman's $r=-0.81, P=5.75 \times 10^{-5}$ ) and the orexin receptor (OXR) (Spearman's $r=-0.68$, $P=1.04 \times 10^{-6}$, Figure $\left.4 \mathrm{~B}\right)$ in serum, which are representative indicators for the inflammatory process and the immune system in serum. The genes within these two gene modules were mainly enriched in the categories of the immune system process (29 genes, $P=2.12 \times 10^{-5}$ ), inflammatory response (16 genes, $P=0.001$ ), immune response (22 genes, $P=0.001$ ), lymphocyte activation (11 genes, $P=0.02$ ), leukocyte activation (11 genes, $P=0.03$ ), and cellular defense response (6 genes, $P=0.02$ ) (Table 1$)$, which suggests that the PMM is a metabolic risk factor. This finding is consistent with evidence that shows that the PMM is supplied by venous blood from the lumbar spine and has lymphatics overlying the muscle from nearby intra-abdominal organs, making it highly susceptible to contiguous infection and inflammation from organs such as the colon, appendix, terminal ileum and several intra-abdominal structures [42-44].

\section{Conclusions}

The analysis presented the gene expression profiles and identified DEGs that may be related to the phenotypic differences in porcine muscles among breeds, between the sexes and the anatomical locations. The results provide a basis for further exploration of the molecular process of muscle fiber type formulation, and may also 
Table 1 Gene Ontology (GO) categories enriched for coexpressed gene modules that correlated with phenotypic traits

\begin{tabular}{|c|c|c|c|c|c|}
\hline $\begin{array}{l}\text { Tissues (gene } \\
\text { module no.) }\end{array}$ & $\begin{array}{l}\text { Correlated } \\
\text { trait }\end{array}$ & $\begin{array}{l}\text { Functional } \\
\text { category }\end{array}$ & Term description & $P$ value & $\begin{array}{l}\text { Involved } \\
\text { gene no. }\end{array}$ \\
\hline \multirow[t]{6}{*}{ LDM (2) } & Apo-A1 & GO-BP & Metabolic process & $1.06 \times 10^{-7}$ & 139 \\
\hline & & GO-BP & Primary metabolic process & $4.55 \times 10^{-8}$ & 127 \\
\hline & & GO-BP & Protein metabolic process & $5.03 \times 10^{-4}$ & 94 \\
\hline & & GO-BP & Carbohydrate metabolic process & 0.028 & 82 \\
\hline & & GO-BP & Protein modification process & 0.016 & 73 \\
\hline & & GO-BP & Protein amino acid phosphorylation & 0.016 & 65 \\
\hline \multirow[t]{5}{*}{ LDM (4) } & LDH & GO-BP & Cellular metabolic process & $5.22 \times 10^{-6}$ & 100 \\
\hline & & GO-BP & Metabolic process & $5.58 \times 10^{-5}$ & 105 \\
\hline & & GO-BP & Cellular process & $2.47 \times 10^{-4}$ & 128 \\
\hline & & GO-BP & Cellular nitrogen compound metabolic process & 0.048 & 60 \\
\hline & & GO-BP & Primary metabolic process & 0.016 & 93 \\
\hline \multirow[t]{14}{*}{ PMM (2) } & OX-B & GO-BP & Immune system process & $2.12 \times 10^{-5}$ & 29 \\
\hline & & GO-BP & Inflammatory response & 0.001 & 16 \\
\hline & & GO-BP & Response to external stimulus & 0.001 & 26 \\
\hline & & GO-BP & Response to wounding & 0.001 & 20 \\
\hline & & GO-BP & Immune response & 0.001 & 22 \\
\hline & & GO-BP & Regulation of immune system process & 0.002 & 16 \\
\hline & & GO-BP & Regulation of response to stimulus & 0.004 & 17 \\
\hline & & GO-BP & Positive regulation of immune system process & 0.006 & 12 \\
\hline & & GO-BP & Regulation of immune response & 0.012 & 12 \\
\hline & & GO-BP & Lymphocyte activation & 0.021 & 11 \\
\hline & & GO-BP & Cell activation & 0.031 & 12 \\
\hline & & GO-BP & Leukocyte activation & 0.033 & 11 \\
\hline & & GO-BP & Positive regulation of lymphocyte activation & 0.049 & 8 \\
\hline & & GO-MF & Receptor binding & $2.19 \times 10^{-5}$ & 30 \\
\hline \multirow[t]{5}{*}{ PMM (4) } & OXR & GO-BP & Immune response & 0.019 & 9 \\
\hline & & GO-BP & Immune system process & $1.79 \times 10^{-6}$ & 16 \\
\hline & & GO-BP & Cellular defense response & 0.027 & 6 \\
\hline & & GO-BP & Response to stimulus & $4.87 \times 10^{-4}$ & 12 \\
\hline & & GO-BP & Cell-matrix adhesion & $2.24 \times 10^{-3}$ & 10 \\
\hline
\end{tabular}

help the further development of biomarkers for important economic traits (i.e. pork quality and yield) in pigs.

\section{Methods}

\section{Sample preparation}

Three females and three males at 210-days-old for each of the leaner Landrace pigs, the wild Tibetan pigs and the fatty Rongchang pigs were used in this study as previously described [18]. Animals were humanely sacrificed, according to the Regulations for the Administration of Affairs Concerning Experimental Animals (Ministry of Science and Technology, China, revised in June 2004) and approved by the Institutional Animal Care and Use Committee in the College of Animal Science and Technology, Sichuan Agricultural University,
Sichuan, China. The longissimus dorsi muscle (LDM, typical white muscle) near the last $3^{\text {rd }}$ or $4^{\text {th }}$ rib and the intermediate section of psoas major muscle (PMM, typical red muscle) were rapidly separated from each carcass. Samples were frozen in liquid nitrogen, and stored at $-80^{\circ} \mathrm{C}$ until RNA extraction. For more information, please refer to Li et al. [18].

\section{Measurements of skeletal muscle-related phenotype}

Measurements of concentrations of 24 serum-circulating indicators of metabolism, myofibre cross-sectional area and myofibre ratio (type I vs. II) are from our previous report based on same individuals. For more information, please refer to Li et al. [18]. 


\section{Extraction of RNA}

Total RNA was extracted from 36 samples using TRIzol (Invitrogen). RNA was purified and DNase treated using an RNeasy column (Qiagen) according to the manufacturer's instructions. The quantity of each RNA sample was examined by the NanoDrop ND-1000 spectrophotometer (Nano Drop) at 260/280 nm (ratio > 2.0). The integrity of total RNA also passed analysis with the Bioanalyzer 2100 and RNA 6000 Nano LabChip Kit (Agilent Technologies) with RIN number $>6$ (7.6 \pm 0.3 , $\mathrm{n}=36)$.

\section{Microarray analyses}

Agilent Oligo microarrays were used to determine global gene expression of 36 samples. Individual microarrays were performed for each sample. Hybridization, washing, and scanning were done according to standard Agilent protocols. Generated array images were loaded into Feature Extraction Software (Agilent Technologies) for feature data extraction, and data analysis was performed with MultiExperiment Viewer (MeV) [45]. Array data have been uploaded to NCBI's Gene Expression Omnibus (GEO) [accession number GSE30343]. For more information, please refer to Li et al. [18].

To obtain high-confidence gene expression data, we mapped 43,603 probes (60 mer in length) to the pig reference genome allowing up to one mismatch, and further filtered unannotated pig target sequences which resulting 4,309 genes were used in subsequent analysis. (Tables S2). To identify differentially expressed mRNAs $(P<0.05)$ for the clustering analysis, we used three-way ANOVA for comparisons. Resulting $P$-values of above tests were corrected with adjusted Bonferroni method (FDR $<0.01,1,000$ permutations).

\section{Construct modules of coexpressed genes}

For LDM and PMM separately, modules of highly coexpressed genes were constructed using pair wise average-linkage cluster analysis as previously described $[8,46]$. We kept repeating this as an iterative process until the most significantly correlated pair was $r<0.8$. To visualize the correlations between probes within the modules, we constructed colored heatmaps by plotting pair-wise correlation values of expression of all the probes within the modules. To calculate significance of overlap in gene content between modules and between different datasets, we performed Fisher's exact tests.

\section{Function enrichment analysis of genes}

To elucidate the biological mechanisms associated with the genes that are correlated to the phenotypic traits, we performed functional enrichment analysis of Gene Ontology (GO) for genes using DAVID software [47].

\section{Quantitative PCR (Q-PCR)}

We selected six genes randomly to validation experiment using Q-PCR. Primer sequences used for the Q-PCR are shown in Additional file 9: Table S6. Porcine $A C T B, T B P$ and $T O P 2 B$ were simultaneously used as endogenous control genes [48]. Relative expression levels of objective mRNAs were calculated using the $\Delta \Delta C$ t method.

\section{Additional files}

Additional file 1: Figure S1. The differences of the (A) myofibre CSA and (B) myofibre ratio among samples. Data are means \pm SD. The significance of differences among samples was determined by the three-way ANOVA; B, $\mathrm{S}$ and $\mathrm{T}$ refer to the breed, sex and tissue, respectively.

Additional file 2: Table S1. Serum parameters of the study population. Datas are means \pm SD. Total cholesterol (TC), triglycerides $(T G)$, high density lipoprotein $(\mathrm{HDL})$, low density lipoprotein $(\mathrm{LDL})$, very-low density lipoprotein (VLDL), lactate dehydrogenase (LDH), apolipoprotein A-1 (Apo-A1), apolipoprotein B (Apo-B), adiponectin (Adipo), adiponectin receptor (AdipoR), C-peptide, cholecystokinin (CCK), gastrin receptor (GsaR), growth hormone (GH), highly sensitive C-reactive protein (hs-CRP), insulin, interleukin - 6 (IL-6), leptin (Lep), leptin receptor (LepR), orexin-B (OX-B), orexin receptor (OXR), plasminogen activator inhibitor-1 (PAl-1), tumor necrosis factor-a (TNF-a) and somatostatin (SS).

Additional file 3: Table S2. Complete gene list used analysis (annotated genes only).

Additional file 4: Table S3. Differential expressed genes among the (A) breeds, between the (B) sexes and the (C) anatomical locations.

Additional file 5: Figure S2. Genes involved in tissue-specific DEGs. Datas are means \pm SD, Student's t-test; LDM and PMM refer to the longissimus doris muscle and psoas major muscle, respectively.

Additional file 6: Figure S3. Validation of gene expression by Q-PCR. The data presented in $\mathrm{Y}$-axis indicated the relative mRNA expression of both microarray and Q-PCR. Datas are means \pm SD. The Pearson correlation coefficient $(r)$ and the corresponding significance value $(P)$ were shown above the columns.

Additional file 7: Table S4. Contents of genes in module generated in (A) longissimus doris muscle (LDM) and (B) psoas major muscle (PMM). For each module, the number genes and the names of all those genes are listed.

Additional file 8: Table S5. Overlap between genes in the modules identified in longissimus doris muscle (LDM) and psoas major muscle (PMM). $P$-values to determine the significance of the overlap between the modules were performed using a Fisher's exact test: ${ }^{*} 1: P=1.45 \times 10^{-}$ ${ }^{10} ;{ }^{*} 2: P=3.39 \times 10^{-12} ;{ }^{*} 3: P=3.29 \times 10^{-18} ;{ }^{*} 4: P=3.38 \times 10^{-18} ; * 5: P=1.09 \times$ $10^{-2} ;{ }^{*} 6: P=7.24 \times 10^{-15} ;{ }^{*} 7: P=9.52 \times 10^{-5} ;{ }^{*} 8: P=1.62 \times 10^{-4}$.

Additional file 9: Table S6. Primer sequences used for Q-PCR. *: ACTB ( $\beta$ actin), TBP (TATA box binding protein) and TOP2B (topoisomerase II $\beta$ ) are the endogenous control genes.

\section{Competing interests}

The authors have declared that no competing interests exist.

\section{Authors' contributions}

MZL and XWL conceived and designed the experiment. JZ and MZL performed the data analysis and drafted the manuscript. AAJ, LZ, SRS and JYW collected the samples, statistical analysis and prepared nucleic acids. CWZ, JDM and LC performed gene expression microarray. All authors read and approved the final manuscript.

\section{Acknowledgments}

This work was supported by grants from the Specialized Research Fund of Ministry of Agriculture of China (NYCYTX-009), the Project of Provincial Twelfth Five Years' Animal Breeding of Sichuan Province (2011YZGG15) and the National Special Foundation for Transgenic Species of China (2011ZX08006-003) 
to X.L., the National High Technology Research and Development Program of China (863 Program) (2013AA102502) to M.L., the Chongqing Fund for Distinguished Young Scientists (CSTC2010BA1007) to J.W.

\section{Author details}

${ }^{1}$ Institute of Animal Genetics \& Breeding, College of Animal Science \& Technology, Sichuan Agricultural University, Ya'an, Sichuan 625000, China.

${ }^{2}$ Chongqing Academy of Animal Science, Chongqing 402460, China.

Received: 11 March 2013 Accepted: 7 June 2013

Published: 15 June 2013

\section{References}

1. Motta VF, de Lacerda CAM: Beneficial Effects of Exercise Training (Treadmill) on Body Mass and Skeletal Muscle Capillaries/Myocyte Ratio in C57BL/6 Mice Fed High-Fat Diet. Int J Morpho 2012, 30(1):205-210.

2. Matsakas A, Patel K: Skeletal muscle fibre plasticity in response to selected environmental and physiological stimuli. Histol Histopathol 2009, 24(5):611-629.

3. Choi $Y$, Kim B: Muscle fiber characteristics, myofibrillar protein isoforms, and meat quality. Livest Sci 2009, 122(2):105-118.

4. Kim NK, Joh JH, Park HR, Kim OH, Park BY, Lee CS: Differential expression profiling of the proteomes and their mRNAs in porcine white and red skeletal muscles. Proteomics 2004, 4(11):3422-3428.

5. Pette D, Staron R: Cellular and molecular diversities of mammalian skeletal muscle fibers. Rev Physiol Biochem Pharmacol 1990, 116:1-76.

6. Campbell WG, Gordon SE, Carlson CJ, Pattison JS, Hamilton MT, Booth FW: Differential global gene expression in red and white skeletal muscle. Am J Physiol Cell Physiol 2001, 280(4):C763-C768.

7. Mo K, Razak Z, Rao P, Yu Z, Adachi H, Katsuno M, Sobue G, Lieberman AP, Westwood JT, Monks DA: Microarray analysis of gene expression by skeletal muscle of three mouse models of Kennedy disease/spinal bulbar muscular atrophy. PLoS One 2010, 5(9):e12922.

8. Wolfs M, Rensen S, Bruin-Van Dijk E, Verdam F, Greve JW, Sanjabi B, Bruinenberg M, Wijmenga C, Van Haeften T, Buurman W: Co-expressed immune and metabolic genes in visceral and subcutaneous adipose tissue from severely obese individuals are associated with plasma HDL and glucose levels: a microarray study. BMC Med Genomics 2010, 3(1):34.

9. Laughlin $\mathrm{MH}$, Schrage WG, McAllister RM, Garverick $H$, Jones A: Interaction of gender and exercise training: vasomotor reactivity of porcine skeletal muscle arteries. J Appl Physiol 2001, 90(1):216-227.

10. Laughlin MH, Welshons WV, Sturek M, Rush JWE, Turk JR, Taylor JA, Judy BM, Henderson KK, Ganjam V: Gender, exercise training, and eNOS expression in porcine skeletal muscle arteries. J Appl Physiol 2003, 95(1):250-264.

11. Glenmark B, Nilsson M, Gao H, Gustafsson J $\AA$, Dahlman-Wright K, Westerblad H: Difference in skeletal muscle function in males vs. females: role of estrogen receptor- $\beta$. Am J Physiol Endocrinol Metab 2004, 287(6):E1125-E1131.

12. Roth SM, Ferrell RE, Peters DG, Metter EJ, Hurley BF, Rogers MA: Influence of age, sex, and strength training on human muscle gene expression determined by microarray. Physiol Genomics 2002, 10(3):181-190.

13. Prather RS, Shen M, Dai Y: Genetically modified pigs for medicine and agriculture. Biotechnol Genet Eng Rev 2008, 25(1):245-265.

14. Rocha D, Plastow G: Commercial pigs: an untapped resource for human obesity research? Drug Discov Today 2006, 11(11-12):475-477.

15. Andersson L: How selective sweeps in domestic animals provide new insight into biological mechanisms. J Int Medicine 2011, 271(1):1-14.

16. Bai Q, McGillivray C, Da Costa N, Dornan S, Evans G, Stear M, Chang KC: Development of a porcine skeletal muscle cDNA microarray: analysis of differential transcript expression in phenotypically distinct muscles. BMC Genomics 2003, 4(1):8-15.

17. Li Y, Xu Z, Li H, Xiong Y, Zuo B: Differential transcriptional analysis between red and white skeletal muscle of Chinese Meishan pigs. Int J Biol Sci 2010, 6(4):350-360.

18. Li M, Wu H, Luo Z, Xia Y, Guan J, Wang T, Gu Y, Chen L, Zhang K, Ma J, et al: An atlas of DNA methylomes in porcine adipose and muscle tissues. Nat Commun 2012, 3:850.

19. Trendelenburg AU, Meyer A, Rohner D, Boyle J, Hatakeyama S, Glass DJ: Myostatin reduces Akt/TORC1/p70S6K signaling, inhibiting myoblast differentiation and myotube size. Am J Physiol Cell Physiol 2009, 296(6):C1258-C1270.

20. Hasty P, Bradley A, Morris JH, Edmondson DG, Venuti JM, Olson EN, Klein WH: Muscle deficiency and neonatal death in mice with a targeted mutation in the myogenin gene. Nature 1993, 364(6437):501-506.

21. Nabeshima Y, Hanaoka K, Hayasaka M, Esuml E, Li S, Nonaka I: Myogenin gene disruption results in perinatal lethality because of severe muscle defect. Nature 1993, 364(6437):532-535.

22. Kambadur R, Sharma M, Smith TP, Bass JJ: Mutations in myostatin (GDF8) in double-muscled Belgian Blue and Piedmontese cattle. Genome Res 1997, 7(9):910-916

23. Rivera-Ferre MG, Aguilera JF, Nieto R: Muscle fractional protein synthesis is higher in Iberian than in Landrace growing pigs fed adequate or lysinedeficient diets. J Nutr 2005, 135(3):469-478

24. Senaeme C, Istasse L, Baldwin P, Gabriel A, Haan V, Bienfait JM: Muscle protein turnover in young bulls in relation to breed and hormonal status. Asian-Austral J Animal Sci 1989, 2(3):200-201.

25. Vidal-Puig A, Solanes G, Grujic D, Flier JS, Lowell BB: UCP3: an uncoupling protein homologue expressed preferentially and abundantly in skeletal muscle and brown adipose tissue. Biochem Biophys Res Commun 1997, 235(1):79-82.

26. Louis M, Van Beneden R, Dehoux M, Thissen JP, Francaux M: Creatine increases IGF-I and myogenic regulatory factor mRNA in $C_{2} C_{12}$ cells. FEBS Lett 2004, 557(1):243-247.

27. Cagnazzo M, Te Pas MF, Priem J, De Wit AA, Pool MH, Davoli R, Russo V: Comparison of prenatal muscle tissue expression profiles of two pig breeds differing in muscle characteristics. J Anim Sci 2006, 84(1):1-10.

28. Cadoudal T, Distel E, Durant S, Fouque F, Blouin JM, Collinet M, Bortoli S, Forest C, Benelli C: Pyruvate dehydrogenase kinase 4: regulation by thiazolidinediones and implication in glyceroneogenesis in adipose tissue. Diabetes 2008, 57(9):2272-2279.

29. Muthny T, Kovarik M, Sispera L, Tilser I, Holecek M: Protein metabolism in slow- and fast-twitch skeletal muscle during turpentine-induced inflammation. Int J Exp Pathol 2008, 89(1):64-71.

30. Auclair D, Garrel DR, Chaouki Zerouala A, Ferland LH: Activation of the ubiquitin pathway in rat skeletal muscle by catabolic doses of glucocorticoids. Am J Physiol 1997, 272(3):C1007-1016.

31. Cleveland BM, Evenhuis JP: Molecular characterization of atrogin-1/F-box protein-32 (FBXO32) and F-box protein-25 (FBXO25) in rainbow trout (Oncorhynchus mykiss): Expression across tissues in response to feed deprivation. Comp Biochem Physiol B Biochem Mol Biol 2010, 157(3):248-257.

32. Wang $\mathrm{X}, \mathrm{Hu} \mathrm{Z}, \mathrm{Hu} J, \mathrm{Du} J$, Mitch WE: Insulin resistance accelerates muscle protein degradation: Activation of the ubiquitin-proteasome pathway by defects in muscle cell signaling. Endocrinology 2006, 147(9):4160-4168

33. Reid MB: Response of the ubiquitin-proteasome pathway to changes in muscle activity. Am J Physiol Regul Integr Comp Physiol 2005, 288(6):R1423-R1431.

34. Agrawal P, Chen Y-T, Schilling B, Gibson BW, Hughes RE: Ubiquitin-specific Peptidase 9, X-linked (USP9X) Modulates Activity of Mammalian Target of Rapamycin (mTOR). J Biol Chem 2012, 287(25):21164-21175.

35. Chang $Y, Y u Y$, Wang N, Xu Y: Cloning and characterization of syap1, a down regulated gene in human hepatocellular carcinoma. Shi Yan Sheng Wu Xue Bao 2001, 34(4):319-322.

36. Lahn BT, Page DC: Functional coherence of the human Y chromosome. Science 1997, 278(5338):675-680.

37. Brocker C, Carpenter C, Nebert DW, Vasiliou V: Evolutionary divergence and functions of the human acyl-CoA thioesterase gene ( ACOT ) family. Hum Genomics 2010, 4(6):411-420.

38. Hakme A, Huber A, Dolle P, Schreiber V: The macroPARP genes Parp-9 and Parp-14 are developmentally and differentially regulated in mouse tissues. Dev Dyn 2008, 237(1):209-215

39. Lourim D, Lin JJ-C: Apolipoprotein A-1 expression is resistant to dimethyl sulfoxide inhibition of myogenic differentiation. Exp Cell Res 1991, 197(1):57-65.

40. Bass A, Brdiczka D, Eyer P, Hofer S, Pette D: Metabolic differentiation of distinct muscle types at the level of enzymatic organization. Euro $J$ Biochem 1969, 10(2):198-206

41. Ryu Y, Kim B: The relationship between muscle fiber characteristics, postmortem metabolic rate, and meat quality of pig longissimus dorsi muscle. Meat Sci 2005, 71(2):351-357. 
42. Crum-Cianflone NF: Bacterial, fungal, parasitic, and viral myositis. Clin Microbiol Rev 2008, 21(3):473-494.

43. Itskowitz MS, Jones SM: GI Consult: Appendicitis. Emerg Med 2004, 36(10):10-15.

44. Miller T, Al-Lozi M, Lopate G, Pestronk A: Myopathy with antibodies to the signal recognition particle: clinical and pathological features. I Neurol Neurosurg Psychiatry 2002, 73(4):420-428.

45. Saeed A, Sharov V, White J, Li J, Liang W, Bhagabati N, Braisted J, Klapa M, Currier T, Thiagarajan M: TM4: a free, open-source system for microarray data management and analysis. Biotechniques 2003, 34(2):374-378.

46. Li M, Wu H, Wang T, Xia Y, Jin L, Jiang A, Zhu L, Chen L, Li R, Li X: Comethylated Genes in Different Adipose Depots of Pig are Associated with Metabolic, Inflammatory and Immune Processes. Int J Biol Sci 2012, 8(6):831-837.

47. Da Huang W, Sherman BT, Lempicki RA: Systematic and integrative analysis of large gene lists using DAVID bioinformatics resources. Nat Protoc 2009, 4(1):44-57.

48. Erkens T, Van Poucke M, Vandesompele J, Goossens K, Van Zeveren A, Peelman $L$ : Development of a new set of reference genes for normalization of real-time RT-PCR data of porcine backfat and longissimus dorsi muscle, and evaluation with PPARGC1A. BMC Biotechnol 2006, 6(1):41-48.

doi:10.1186/1471-2156-14-53

Cite this article as: Zhang et al:: Breed, sex and anatomical locationspecific gene expression profiling of the porcine skeletal muscles. BMC Genetics 2013 14:53.

\section{Submit your next manuscript to BioMed Central and take full advantage of:}

- Convenient online submission

- Thorough peer review

- No space constraints or color figure charges

- Immediate publication on acceptance

- Inclusion in PubMed, CAS, Scopus and Google Scholar

- Research which is freely available for redistribution 